\title{
Glucose handling during menstrual cycle
}

\author{
Amruta S. Bennal ${ }^{1 *}$, Sudha Biradar Kerure ${ }^{2}$ \\ ${ }^{1}$ Assistant Professor in Physiology, ${ }^{2}$ Associate Professor in Obstetrics and Gynecology, Navodaya Medical College, \\ Raichur, India
}

Received: 23 April 2013

Accepted: 10 May 2013

*Correspondence:

Dr. Amruta S. Bennal,

E-mail: amrutabennal@gmail.com

(C) 2013 Bennal AS et al. This is an open-access article distributed under the terms of the Creative Commons Attribution Non-Commercial License, which permits unrestricted non-commercial use, distribution, and reproduction in any medium, provided the original work is properly cited.

\begin{abstract}
Background: Menstrual cycle is a physiological phenomenon during reproductive life of women. Its phases are influenced by alteration in the concentration of hormones such as estrogen and progesterone. Certain physiological parameters, such as blood glucose are affected during menstrual cycle. So our study includes estimating FBS and PPBS ( 2 hour after OGTT) in different phases of menstrual cycle. The objective of this study was to know the effect of different phases of menstrual cycle on glucose metabolism in younger age group.

Methods: A Cross-sectional and descriptive study was conducted in 50 normal menstruating women with age 18 to 22 years and with normal BMI. Statistical analysis was done by using student " $t$ " test.

Results: There is no significant change in FBS levels during different phases of menstrual cycle. There is significant change in PPBS levels during secretory phase comparing with proliferative phase and menstrual phase.

Conclusion: During secretory phase, individuals are prone for having higher blood glucose levels comparing to other phases. So this phenomenon should be considered for comparative studies and diagnosing pathological conditions.
\end{abstract}

Keywords: Menstrual cycle, Fasting blood sugar, Postprandial blood sugar

\section{INTRODUCTION}

Menstrual cycle is a physiological phenomenon during reproductive life of women. Its phases are influenced by alteration in the concentration of hormones such as estrogen and progesterone. ${ }^{1}$ Therefore, certain physiological parameters, such as blood glucose is affected during menstrual cycle. In healthy non diabetic women, some investigators have reported a worsening in glucose tolerance, as assessed by the oral glucose tolerance test (OGTT), during the luteal phase (secretory phase) ${ }^{2,3}$ However, other studies that used the OGTT ${ }^{4,5}$ or the intravenous glucose tolerance test ${ }^{6}$ did not find significant changes in glucose tolerance or insulin concentration as a function of the menstrual cycle phase. Evaluation of insulin sensitivity by means of the euglycemic-hyperinsulinemic clamp technique has failed to detect alterations during the luteal phase (secretory phases) in nondiabetic women. ${ }^{7,8}$ Women with type 1 diabetes, frequently report problems with blood glucose control around the time of menstruation. ${ }^{9}$ There are studies done in women with type 1 diabetes mellitus, and also there are controversies about blood glucose level in different phases of menstruation. So we have taken this study in younger age group, who have normal BMI, to know the effect of different phases of menstrual cycle on glucose metabolism.

\section{METHODS}

This study was conducted in the Department of Physiology, Navodaya medical college (NMC) Raichur, with the help of Obstetrics and Gynecology Department, NMC, Raichur and with the assistance of laboratory setup of the Department of Biochemistry, NMC, Raichur. The study and its conduct were cleared by the ethical committee, NMC, Raichur. 
The study was done by obtaining blood samples from study group attending OPD, in Obstetrics and Gynecology (OBG) Department, NMC Raichur, during study period, June 2012 - March 2013.

The study group consists of 50 normal menstruating women, with age group 18 to 22 years, with regular menstrual cycle, attending the OPD of OBG Department, NMC, Raichur. Menstruating women with irregular menstrual cycle were excluded from study.

Previous history of hypertension, Diabetes Mellitus, renal disease, thyroid disorder dyslipidemia, any disease affecting blood glucose level were excluded from study. Subjects with family history of diabetes mellitus were excluded from study. After selecting the subjects, informed consent was taken. Height and weight of the individuals were measured. BMI was calculated as per formula: Weight $(\mathrm{Kg}) /$ Height (meter) ${ }^{2}$ (Quetelet's Index).

The subjects were examined for vital signs, Pulse, Blood pressure. All vital parameters were within normal physiological limit. After giving proper instructions, subjects underwent OGTT (oral glucose tolerance test) with 75 gram of glucose during different phases of menstrual cycle like proliferative phase, secretory phase, and menstrual phase. $2 \mathrm{ml}$ of fasting blood sample was collected by venepuncture under aseptic precaution for fasting blood sugar (FBS). 75 gram of glucose was given with $300 \mathrm{ml}$ of water to drink. After 2 hours, blood sample was collected by venepuncture under aseptic precaution, for post prandial blood sugar (PPBS). Sample was analyzed in Biochemistry Lab, in NMC, Raichur, with clinical chemistry Analyzer. Analysis was done for fasting blood sugar (FBS) and post prandial blood sugar (PPBS).

\section{The Statistical Analysis}

The results were expressed in terms of mean $\pm \mathrm{SD}$. The test of significance used was student " $t$ " test and a " $p$ " value less than 0.05 was considered statistically significant.

\section{RESULTS}

Cross-sectional and descriptive study was undertaken in 50 regular menstruating women. All the women belonging to the age group 18 to 22 years and have BMI $21.46 \pm 0.76 \mathrm{~kg} / \mathrm{m}^{2}$. FBS and PPBS during different phases of menstrual cycle are represented in the table.

Table 1: FBS and PPBS levels in different phases of menstrual cycle.

\begin{tabular}{|lll|}
\hline Parameter & $\begin{array}{l}\text { FBS }(\mathrm{mg} / \mathrm{dl}) \\
{[\mathrm{mean} \pm \mathrm{SD}]}\end{array}$ & $\begin{array}{l}\text { PPBS }(\mathrm{mg} / \mathrm{dl}) \\
{[\mathrm{mean} \pm \mathrm{SD}]}\end{array}$ \\
\hline Menstrual phase & $80.44 \pm 6.90$ & $106.60 \pm 5.39$ \\
\hline Proliferative phase & $81.02 \pm 7.65$ & $111.96 \pm 8.48$ \\
\hline Secretory phase & $81.14 \pm 10.15$ & $119.72 \pm 8.80$ \\
\hline
\end{tabular}

Table 2: FBS and PPBS levels in menstrual phase and proliferative phase.

\begin{tabular}{|llllll|}
\hline Parameter & $\begin{array}{l}\text { Menstrual } \\
\text { phase[mean } \pm \text { SD] }\end{array}$ & $\begin{array}{l}\text { Proliferative } \\
\text { phase[mean } \pm \text { SD] }\end{array}$ & 't' value & 'p' value & Significance \\
\hline FBS $(\mathrm{mg} / \mathrm{dl})$ & $80.44 \pm 6.90$ & $81.02 \pm 7.65$ & 0.396 & $>0.05$ & NS \\
\hline PPBS $(\mathrm{mg} / \mathrm{dl})$ & $106.60 \pm 5.39$ & $111.96 \pm 8.48$ & 0.694 & $>0.05$ & NS \\
\hline
\end{tabular}

NS- Not significant

Table 3: FBS and PPBS in menstrual phase and secretory phase.

\begin{tabular}{|llllll|}
\hline Parameter & $\begin{array}{l}\text { Menstrual } \\
\text { phase[mean } \pm \text { SD] }\end{array}$ & $\begin{array}{l}\text { Secretory phase } \\
{[\text { mean } \pm \text { SD] }}\end{array}$ & 't' value & 'p' value & Significance \\
\hline FBS $(\mathrm{mg} / \mathrm{dl})$ & $80.44 \pm 6.90$ & $81.14 \pm 10.15$ & 0.408 & $>0.05$ & NS \\
\hline PPBS $(\mathrm{mg} / \mathrm{dl})$ & $106.60 \pm 5.39$ & $119.72 \pm 8.80$ & 10.339 & 0.001 & HS \\
\hline
\end{tabular}

NS- Not significant, HS- Highly significant

Table 4: FBS and PPBS in proliferative phase and secretory phase.

\begin{tabular}{|llllll|}
\hline Parameter & $\begin{array}{l}\text { Proliferative } \\
\text { phase[mean } \pm \text { SD] }\end{array}$ & $\begin{array}{l}\text { Secretory phase } \\
{[\text { mean } \pm \text { SD] }}\end{array}$ & 't' value & 'p' value & Significance \\
\hline FBS $(\mathrm{mg} / \mathrm{dl})$ & $81.02 \pm 7.65$ & $81.14 \pm 10.15$ & 0.085 & $>0.05$ & NS \\
\hline PPBS $(\mathrm{mg} / \mathrm{dl})$ & $111.96 \pm 8.48$ & $119.72 \pm 8.80$ & 4.717 & 0.01 & HS \\
\hline
\end{tabular}

NS- Not significant, HS- Highly significant 
Fasting Blood Sugar (FBS) and Post Prandial Blood Sugar (PPBS) after 2 hour with $75 \mathrm{gm}$ OGTT were within normal limits in three phases of menstrual cycle. There is no significant change in FBS in different phases of menstrual cycle. There is highly significant change in PPBS in secretory phase comparing with proliferative phase and menstrual phase, but there is no significant change in PPBS in proliferative phase comparing to menstrual phase.

\section{DISCUSSION}

The study was conducted to evaluate changes for fasting blood sugar (FBS) and post prandial blood sugar (PPBS) in different phases of menstrual cycle in normal menstruating women, aged 18 to 22 years, with normal BMI and without any predisposing factors for Diabetes Mellitus.

Menstrual cycle is characterized by three phases; occur due to alteration in concentration of hormones such as estrogen and progesterone. Estrogen and progesterone levels will be very low in menstrual phase. During the proliferative phase, there is an increased level of estrogen and the secretory phase is characterized by raised levels progesterone and also estrogen.

During the Secretory phase, there is slight rise in Fasting Blood sugar comparing to, proliferative phase and menstrual phase, but it is not significant statistically. Post Prandial Blood sugar is raised in secretory phase comparing with proliferative phase and menstrual phase, and it is significant statistically. Alterations in insulin receptor binding and affinity at different times during the menstrual cycle have been reported as a potential explanation for his phenomenon. Windom et al (1992) concluded that poor blood glucose control was correlated with decreased insulin sensitivity and high estrogen levels in the luteal phase (secretory phase) ${ }^{10}$ and other studies suggest high progesterone levels. ${ }^{11}$

Observed changes in glucose levels in different phases of menstrual cycle may be due to effect of hormones progesterone and estrogen throughout the menstrual cycle. $^{12}$ One theory says that increased levels of progesterone cause increased insulin resistance, which in turn leads to hyperglycemia, while the decrease of glucose concentration during follicular phase can be concerned to high estrogen causing increased insulin sensitivity. ${ }^{13}$ Possible mechanisms that lead to decreased insulin sensitivity during secretory phase may be due to increased progesterone levels, which have been shown in several of in vitro animal studies. In rats, progesterone impairs, glucose uptake in skeletal muscle and adipose tissue. $^{14,15}$

The changes in metabolic control during the menstrual cycle are probably attributable to mechanisms other than variations in insulin sensitivity. ${ }^{9}$ It may be due to low grade inflammation before onset of menses, and premenstrual symptoms. Trout has observed decreased insulin sensitivity with increasing premenstrual symptoms. $^{11}$

Altered hormonal concentrations, along with other mechanisms, may be responsible for changes occurring in glucose level during different phases of menstrual cycle. Changes observed should be taken as physiological, while doing comparative studies and should be kept in view while diagnosing pathological conditions.

\section{REFERENCES}

1. Arthur C, Guyton AC, Hall JE. Textbook of Medical Physiology. 11th edition. Elsevier Saunders, Philadelphia, 2006:1018-9.

2. Roy SK, Ghosh BP, Bhattacharjee SK. Changes in oral glucose tolerance during normal menstrual cycle. J Ind Med Assoc 1971;57:201-4.

3. Jarrett RJ, Graver HJ. Changes in oral glucose tolerance during the menstrual cycle. $\mathrm{Br}$ Med $\mathrm{J}$ 1968;2:528-9.

4. Bonora E, Zavaroni, Alpi O, Pezzarossa A, Dall'Aglio E, Coscelli C, Butturini U. Influence of the menstrual cycle on glucose tolerance and insulin secretion. Am J Obstet Gynecol 1987;157:140-1.

5. Cudworth AG, Veevers A. Carbohydrate metabolism in the menstrual cycle. $\mathrm{Br} \mathrm{J}$ Obstet Gynaecol 1975;82:162-9.

6. Spellacy WN, Carlson KL, Schade SL. Menstrual cycle carbohydrate metabolism. Am J Obstet Gynecol 1967;99:382-6.

7. Yki-Jarvinen H. Insulin sensitivity during the menstrual cycle. J Clin Endocrinol Metab 1984;59:350-3.

8. Toth EL, Suthijamroon A, Crockford PM, Ryan EA. Insulin action does not change during the menstrual cycle in normal women. J Clin Endocrinol Metab 1987;64:74-80.

9. Moberg E, Kollind M, Lins PE, Adamson U. Dayto-day variation of insulin sensitivity in patients with type 1 diabetes: Role of gender and menstrual cycle. Diabetes Med 1995;12:224-8.

10. Windom B, Diamond MP, Simonson DC. Alterations in glucose metabolism during menstrual cycle in women with IDDM. Diabetes Care 1992;15:213-20.

11. Trout KK, Rickels MR, Schutta MH, et al. Menstrual cycle effects on insulin sensitivity in women with type 1 diabetes: a pilot study. Diabetes Technol Ther 2007;9:176-182.

12. Katsuki A, Sumida Y, Murashima S, Fujii M, Ito K, Tsuchihashi K, Murata K, Yano Y, Shima T. Acute and chronic regulation of serum sex hormonebinding globulin levels by plasma insulin concentrations in male noninsulin-dependent diabetes mellitus patients. J Clin Endocrinol Metab 1996;81:2515-9.

13. Ballester J, Muñoz MC, Domínguez J, Rigau T, Guinovart JJ, Rodríguez-Gil JE. Insulin-dependent 
diabetes affects testicular function by FSH- and LHlinked mechanisms. J Androl 2004;25:139-52.

14. Rushakoff RJ, Kalkhoff RK, Effects of pregnancy and sex steroids administration on skeletal muscle metabolism in rat. Diabetes 1981;30:545-50.
15. Sutter-Dub MT, Dazey B, Vergnaud MT, Madec AM. Progesterone and insulin-resistance in the pregnant rat. I. In vivo and in vitro studies. Diabete Metab. 1981 Jun;7(2):97-104.

DOI: $10.5455 / 2320-1770 . i j r \operatorname{cog} 20130905$

Cite this article as: Bennal AS, Kerure SB.

Glucose handling during menstrual cycle. Int J

Reprod Contracept Obstet Gynecol 2013;2:284-7. 